\title{
Goldsworthy's genera
}

Andy Goldsworthy sets out to explore some of the recurring forms in the world around us, using a variety of media drawn from nature itself - snow and sand, twigs and thorns.

\section{Martin Kemp}

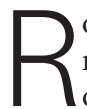
ound holes, often of a tangible blackness, are fringed by miraculous aureoles of glowing autumn leaves. Sometimes the dark apertures are bounded by pebbles, graded in size and colour, while at other times they are hedged in by nests of bleached sticks. Long, thin fissures run jaggedly across layered carpets of leaves and through apparently random arrays of stones. Craters and snaking ridges of sand and soil speak of an organic geometry that blends the rectilinear and curvilinear without dissonance.

Low, vertiginous arches are engineered from raw plates of slate or irregular paving stones of ice, each discrete unit, courtesy of gravity, mutually squeezing its companions into stable unity in the absence of adhesive. A sharp star of shining silvery icicles tiptoes on needle-thin points across abrasive rocks. Cut slits transform a wall of frozen snow into an arctic Stonehenge.

Oval stones and angular rocks balance miraculously over single points. Twigs and thin sticks are woven into spiral bowers or giant cobwebs, as unexpected in pattern as they are paradoxical in their stability. A curved, tapering cornucopia, freshly green, is composed from a continuous spiral of sweet chestnut leaves, its seams stitched with thorns.

\section{The British 'sculptor' Andy Goldsworthy is unrivalled in range and skill as a 'nature artist'. He works as a collabo- rator with natural phenomena during the passing seasons, feeling deep into the essence of soil, stone, water, ice, flower, leaf, stem, stick and trunk.}

He is a maker in the manner of the bowerbird, spider, swallow, bee, shellfish - or, in human terms, the Eskimo, dry-stone waller or oriental master of Zen gardens. Tensile strength is conjured from fragile delicacy, and stable unity is compounded from inchoate members.

In the illustrations, Japanese maple leaves, startlingly carrot in hue, metamorphose from a floating chain one day to become the next a fringed hole supported by a woven briar ring. And blades of grass, creased and arched into a snake of expanding girth, are pinioned to the soil by ranks of thorn rivets.

Goldsworthy creates genera of forms spheres, rings, holes, arches, spires, snakes and fissures - which cut across (sometimes literally) the conventional taxonomies of genus and species. Through sight, touch and motion he searches out, like a latter-day
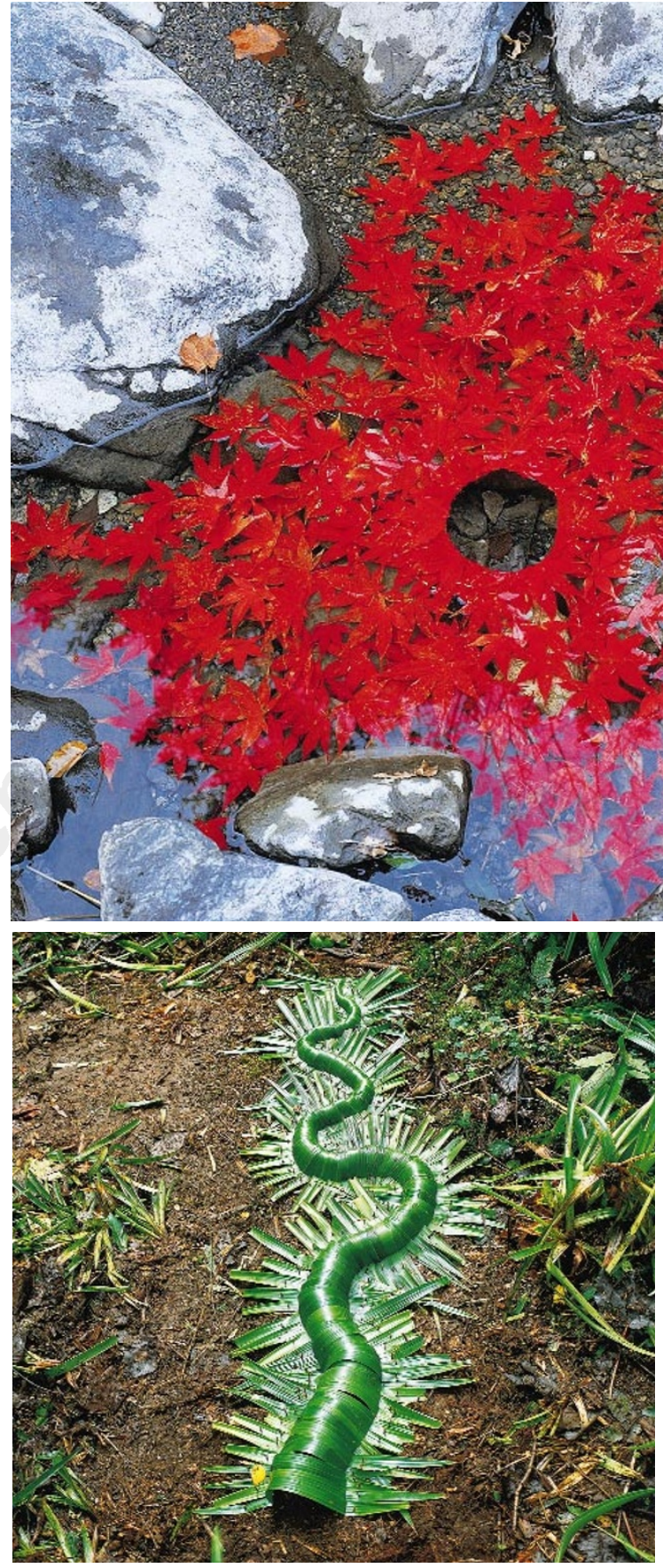

Goldsworthy's Japanese Maple Leaves, Supported by a Woven Briar Ring (above), 1987 (Ouchiyama, Japan).

Blades of Grass, Creased and Arched, Secured with Thorns (left), 1988 (Penpont, Dumfriesshire).
D'Arcy Wentworth Thompson, morphological commonalities which arise from the material and processes of nature. For example, Goldsworthy writes: "Some works have the qualities of snaking but are not snakes... The snake has evolved through a need to move close to the ground, sometimes below and sometimes above, an expression of the space it occupies. This is a potent recurring form in nature which I have explored through working in bracken, snow, sand, leaves, grass, trees, earth. It is the ridge of a mountain, the root of a tree, a river finding its way down a valley."

Across diversity, Goldsworthy sees commonalities, and in complexities he intuits shared shaping. An instinctive dialogue with the sciences of order and disorder is being established.

Martin Kemp is in the Department of the History of Art, University of Oxford, 35 Beaumont Street, Oxford OX1 2PG, UK. 